\title{
A comparative analysis of the changes in nursing practice related to health sector reform in five countries of the Americas
}

\author{
Edilma B. Guevara ${ }^{1}$ and Elnora P. Mendias ${ }^{1}$
}

ABSTRACT Objective. To identify changes in nursing practice and the nursing-practice environment that have occurred with implementation of health sector reform in five countries in the Americas. Methods. An exploratory study of selected settings in Argentina, Brazil, Colombia, Mexico, and the United States of America was conducted between 1997 and 1999 to collect narrative data from 125 professional nurses about their perceptions of nursing practice and changes in work environments. Descriptions of characteristics and trends in nursing practice in the study sites were also obtained.

Results. Reorganization of health services has occurred in all five of the countries, responding to health sector reform initiatives and affecting nursing practice in each country. Respondents from all five countries mentioned an emphasis on private enterprise, changes in payment systems for patients and providers, redistributions in the nursing workforce, changes in the personnel mix and nursing-practice functions, work shifting from the hospital to the community, and greater emphasis on cost control and prevention in practice settings.

Conclusions. The study provides initial information about current nursing issues that have arisen as a result of health care reform initiatives. Regardless of differences in service models or phases of health sector reform implementation, in all the countries the participating nurses identified many common themes, trends, and changes in nursing practice. The driving forces for change and their intensity have been different in the five countries. Nurses maintain their core values despite increased work stress and greater patient care needs in all the countries as well as economic crises in the Latin American countries.

Key words Health care reform, nursing, hospitals, health manpower, delivery of health care.

Improvements in the health status of a population are affected by social and economic factors and by development in areas such as urbanization, employment, nutrition, education, and environment (1). Moreover, popula-

\footnotetext{
1 The University of Texas Medical Branch, School of Nursing, Galveston, Texas, United States of America. Send correspondence to: Edilma B. Guevara, University of Texas Medical Branch, School of Nursing, 301 University Boulevard, Galveston, Texas 77555-1029, United States of America; telephone: (409) 772-5029; fax: (409) 772-5864; e-mail: eguevara@utmb.edu
}

tion health status influences the development of maximum human capacity and productivity. Therefore, the provision of health services may be considered an investment in human capital and a crucial factor for countries' becoming and remaining competitive in a global economy, according to a conference paper by Barillas. ${ }^{2}$

\footnotetext{
Barillas E. Health care reform: global economic and social trends [conference paper]. The Third Millennium Conference, 16 May 1996, Galveston, Texas.
}

This perspective has served as the basis for market-driven health sector reform. However, this philosophical shift and its focus on market concerns has resulted in limited consideration of other aspects such as the needs for a socio-environmental framework for analyzing health status and for humanistic approaches to empowering both health care providers and healthsystem clients.

Health sector reform, in various forms, has affected all aspects of health 
care delivery: objectives, administration, organization, outcome measurement, and payment systems. Nursing personnel and nursing services have been considered the target and means both for cost containment and for quality improvement (2). Nursing personnel comprise a large percentage of health care personnel, and changes in health care organization have altered nurses' practice and work environments. Nurses have had limited participation in the decision-making on the reorganization of their services. Thus, it is vital to obtain more information about how health sector changes are influencing nursing practice, decisionmaking, and regulatory mechanisms.

Although much has been written about health care reform, little is known about how nurses' practice and work environment have changed since the reorganization of health care systems in the 1990s. One urgent need is the identification of relevant concepts and variables related to current nursing practice and work environments, as an initial step in the description of the nature, extent, and magnitude of these changes. In addition, there is a need to develop cross-cultural instruments to study current nursing issues. To address these needs, an exploratory qualitative study was designed to obtain a current cross-cultural view of nursing in selected health settings in five countries of the Americas and to provide information about current trends in nursing practice, education, and regulation. This paper presents a cross-country summary of findings reported by researchers in each of the five participating countries: Argentina, Brazil, Colombia, Mexico, and the United States of America. The study framework $(3,4)$ and the individual country studies (5-11) have been published elsewhere.

\section{MATERIALS AND METHODS}

This multicenter study used a qualitative approach to identify changes in nursing practice and the nursing-practice environment since implementation of health sector reform in the par- ticipating countries. Additional data on external factors (country characteristics) and internal factors (site characteristics) were used to assess the comparability of the study sites.

After study approval by the Institutional Research Board at the University of Texas Medical Branch and institutional review committees at each participating institution, researchers used a purposive sample approach to obtain a sample of at least 10 professional nurses working at participating institutions in each country. (Purposive sampling is commonly used in qualitative research and involves selecting subjects considered typical of the study population (12)). After obtaining informed consent, researchers interviewed participating nurses in depth at least once to obtain narrative data on their perceptions of nurses' practice and work environments as well as descriptions of nursing-practice characteristics and trends. Interviews took place in private in the facilities where the nurses were working. Researchers used a standardized protocol to apply a structured interview guide. The interview guide included questions related to 11 areas, including participants' perceptions about definitions of nursing practice and the social value of nursing, nursing functions and roles, recent changes in nursing practice and the practice of other health care workers, reasons for recent changes, the effect of those changes on nursing practice and patient care, nursing decision-making, and the future of nursing. Interviews were audiotaped, then transcribed verbatim.

Naturalistic inquiry methodology (13) was used to collect and analyze the narrative data in each country. The goal of naturalistic inquiry is not to generalize findings but to present a view of the phenomenon as perceived by participants and researchers.

Goins' Paradigm of Dynamic Interaction (3) was used as the framework to characterize the study sites' internal environment (money, manpower, materials, facilities, and equipment) and external environment (social, technological, economic, ethical, political, legal, and environmental aspects). In addition, health service reorganization was characterized using the health care reform indicators in the Barillas conference paper mentioned earlier.

\section{Data analysis}

The research team in each country was responsible for the analysis of its own data, using the standardized protocol. Data analysis techniques included content analysis, constant comparison, and unitization and categorization of emerging themes as a means to define category labels and generate each country's definition of nursing practice.

According to Lincoln and Guba (13), evaluation of the trustworthiness of qualitative findings may be conducted using four indicators: credibility, transferability, dependability, and confirmability. Credibility was addressed through peer debriefings in two ways: 1) frequent researcher consultations with the project's principal investigator and 2) two researchers' meetings. Transferability or generalizability of findings was achieved by identifying rich segments of data common to all the countries and establishing inter-country agreements about themes. Dependability (stability of findings) and confirmability (neutrality) were achieved by using an audit trail. To ensure consistency of methodology and confirmability of narrative data, a sample of transcripts (translated into English) was reviewed by an expert in qualitative data analysis.

\section{RESULTS}

\section{Study population}

The study population included a total of 125 practicing professional nurses as well as other health professionals, who were interviewed at selected institutions. Included here are results from 20 nurses from Córdoba, Argentina; 42 from Ribeirão Preto, Brazil; 10 from Antioquia, Colombia; 20 from the state of Mexico, Mexico, and 16 from the state of Nuevo León, 
Mexico; and 17 from the state of Texas, United States. The researchers in each country described the characteristics of the nurses whom they interviewed.

\section{Structural characteristics}

Structural characteristics are summarized using Goins' Paradigm of Dynamic Interaction (3), which includes such institutional resources as manpower, money, materials, facilities, and equipment. Researchers in all the countries had difficulty obtaining specific information about financial and material resources at the study sites. A mix of private and public funding existed in all the study sites. In all five countries, federal, state, and municipal governments funded public hospitals and clinics. Private services used insurance, prepaid, or fee-for-services plans.

Reflecting regional trends, with the exception of the United States, most of the study sites had a low percentage of nurses as compared to nurse auxiliaries or nurse's aides. The proportion of nurses with a baccalaureate degree, which requires four to five years of full-time university education, was low in all the countries except the United States. In the four Latin American countries, public institutions reported a higher percentage of baccalaureate-prepared nurses than did private facilities. One reported trend was a decreasing number of nursing personnel. Another trend was shortterm contracting of nursing personnel to work in specific programs or projects, instead of hiring them for stable full-time positions. Salaries had been diminished or frozen in Argentina and Colombia.

Although there were some variations and some missing data across the countries, in comparing private and public settings, the study found that public sites were more likely than private sites to report insufficient materials and supplies. The renovation and maintenance of public hospitals varied within all the countries, but it tended to have decreased in all the countries except the United States. Private sites were reported to be adequate and well maintained. Varying degrees of technology were found in public hospitals, ranging from state-of-the-art technology in the United States to limited technology in the other four countries. Private facilities were well equipped, including with equipment for hightech procedures.

\section{Reorganization of health services}

Health services had been reorganized in all five countries in response to health care reform initiatives. Those reform initiatives are summarized below, using Barillas' health care reform indicators, which include decentralization, self-initiatives, changes in private and public funding, basic health packages, and target populations (4).

Decentralization has occurred in all five countries, with a shifting of control from federal to state and local levels (5-11).

Self-initiatives are efforts directed toward increasing management capability and decision-making at the state and local levels (4). Self-initiatives focusing heavily on institutional financing have been a by-product of competition between the public and private sectors in efforts to control costs or to subsidize health services for the underserved. In all the countries, selfmanagement has allowed public health institutions to charge for health care services that they provide to the members of private health care plans or of other plans.

A mix of private and public funding for health care existed in all the study sites, with private financing exceeding public financing. The level of private financing ranged from $53 \%$ in Mexico (8) to $70 \%$ in Colombia (7).

Basic health packages are selected health services that are designated as the minimal health services for a targeted population. The four Latin American countries had identified basic packages, which usually included preventive health and health promotion services for vulnerable populations such as women and children, the elderly, and the poor (5-10). The United States has not designated a specific basic package but has implemented a number of health programs with similarities to basic packages, in that comparable services and populations are identified. ${ }^{3}$ The trend in all the countries was to encourage preventive and health promotion services.

Targeted populations in all the countries have included the indigent and uninsured. Women and children have been considered high-risk groups in Argentina (5), Brazil (14), Colombia (7), Mexico (15), and the United States. ${ }^{3}$ The elderly have been targeted in Brazil (6), Colombia (14), Mexico (15), and the United States (16). Specific services have been targeted to indigenous groups in Brazil (17), Mexico (15), and the United States (18).

In summary, the study sites appeared to differ in the characteristics of the populations served and the extent of health care reorganization. These facts were considered in interpreting and comparing the study findings.

\section{Changes in nursing practice}

The study's data analysis included identifying major thematic areas related to changing nursing work environments and responsibilities. Even though the characteristics varied among the study sites, we identified several common categories of recent changes in nursing practice.

More work in less time with fewer staff. Some nurses mentioned a decrease in the nursing workforce, different duties, extended use of auxiliary personnel, or reductions in other job positions that impact nursing tasks. Specific comments included: "There is an immense accumulation of work," "There is more pressure on everybody to do more with less," and "There seems to be less time and less staff. My workload is greatly increased, and there is no one to help me."

\footnotetext{
Goins PN. US STEEPLE framework. Paper presented at Pan American Health Organization Researcher Group, University of Texas Medical Branch, March 1998, Galveston, Texas.
} 
More paperwork. Nurses reported having to do large amounts of paperwork as well as performing responsibilities once assigned to others. One nurse commented, "No one has picked up any of my responsibilities." Another nurse said, "We have picked up more of what different people used to do." In addition, the amount of paperwork requested from the clients has complicated the health care system, including the delivery of nursing care.

Less direct patient care. Nurses mentioned increased workloads affecting their practice, including reduced time for direct patient care despite increased patient acuity. For example, one nurse said, "Now we have fewer nurses to take care of an increasing number of patients who are coming in worse conditions, poorer, and with more serious deterioration in their personal appearance and nutrition."

More administrative duties. Nurses cited increased administrative responsibilities. "There is a big change," one nurse said, "and responsibility has increased. You have to supervise several workers now." The need for selffinancing also affects nursing and nurses' administrative duties. One nurse reported, "We have to implement a billing system for the community activities in order to obtain financial resources."

Increased demand for technological knowledge. Nurses in all five countries felt a demand for knowledge based on technological advances and new work settings, as well as administrative expectations for continuing professional growth. Some nurses mentioned the impact of computers. One nurse commented, "Doctors and nurses are using Windows 95 [computer operating system], and we have to get into the computer all the time, to check out orders and do chart checks that way." Another nurse commented, "You have to keep up with computers and the other changes that are occurring in medicine." Nurses also mentioned educational expectations. One nurse said, "They are pushing us to have continu- ing education and to be up to date in all theoretical and practice aspects; [everything is] an innovation."

Clients who are more informed, educated, and demanding. Nurses expressed the need to be more knowledgeable about disease processes and about sophisticated technology, to respond to both market demands and population characteristics. One nurse said: "People are starting to understand their values and needs. They are more demanding. He [the patient] knows what he wants and can get. More access to information is making an internal revolution."

\section{Changes in the nursing work environment}

Dominant themes in each of the countries. The study identified dominant themes in work environment changes in each country.

In Argentina these themes included increased workloads, decreased job security, insufficient supplies, low salaries, increased demand for technological knowledge, and the need for nurses to hold two jobs in order to support their families.

Themes in Brazil included redirection of resources, supplies, and technology from hospital to ambulatory care; the need for a more cohesive workforce, in which interaction and communication among various disciplines are facilitated; increased service demands, with greater client needs and fewer nursing personnel available to meet those needs; increased workloads; job dissatisfaction among hospital nurses; low salaries; the need to hold two jobs; more paperwork in private institutions; and reduced supplies and equipment in public hospitals.

Among the themes in Colombia were increased workload, fragmented services that decrease health care continuity, insufficient numbers of nurses, poor work conditions, low salaries, and job dissatisfaction. Another theme was having less time to spend providing nursing care to clients, due to such reasons as paper- work, administrative duties, and fewer nursing personnel.

In Mexico the themes included decreased time for care, heavy workloads, low salaries, increased responsibilities, too few nurses to meet increased service demands, increased paperwork, and more technology.

The themes in the United States included doing more with less, heavy paperwork, more time spent managing and less time spent providing direct care, more time directing the work of unskilled staff, insufficient supplies, and managed care. Nurses indicated that managed care dictated reimbursable services, which increased nurses' time spent in completing paperwork and in documenting clients health needs, which were needed to ensure reimbursement. Also, restrictions on reimbursement for supplies and equipment affected client care.

\section{Common categories of factors affecting nursing work environments}

The study also identified common categories of factors affecting nursing work environment across the countries.

Insufficient resources. Nurses mentioned insufficient resources for adequate patient services. One nurse said: "Materials are much scarcer. They demand a series of things, but the elements are not provided to accomplish them. The only thing that this creates is chaos within personnel of the entire health team." Another nurse said: "Sometimes we do not have anything to work with. There are no disposable materials, clothing, medicines, but they put in the latest-generation devices." Nurses in some countries commented that patients are expected to provide their own syringes or other supplies, occasionally resulting in a crisis. According to one nurse, "There was a period of big crisis when a mother gave birth to a baby without anything in which to dress the baby."

Lack of service availability. Restrictions in service provision were also felt to be a problem. One nurse said, 
"Sometimes it is hard to explain [to patients] that there are no openings that day for them to be seen." Another nurse said: "[At night] the medical clinic is closed, and no patients can be accepted. Where do these patients go?" A third nurse commented, "There are times when we cannot accept more people, as we are full."

Stressful conditions or work-related stress. This lack of service availability created stress for both nurses and patients. One nurse said: "People are being turned away and they don't even have access to the care of the nurses or physicians because they can't access us. Once they do get through, they are angry." Another nurse reported: "Sometimes the patient says he is going to a radio station to complain [about lack of service], and they really call the radio stations! This is really stressful." One nurse said that patients may feel that "we really don't care that much about them, because we just don't take enough time to spend with them and really know what is going on."

Job dissatisfaction. Some nurses reported conditions leading to job dissatisfaction, such as with salaries not being paid. "Some think," said one nurse, "that because they make less money, they should not work as hard. [Delayed worker payment has created conditions where] several workers on the nursing and medical staff wanted to stop working. This interferes with our routine and harms the patient."

\section{Changes in the labor market}

The study also identified common trends in the labor market of the participating countries.

Changes in the nursing workforce. Nurses mentioned fewer nurses employed, different duties, the extended use of auxiliary personnel, and reductions in other job positions that impact nursing tasks and job security. In Argentina, Brazil, and Colombia, concerns were related to reductions or freezes in the number of nursing posi- tions. In the United States, nurses mentioned concerns related to unlicensed or uncertified personnel, who needed more supervision and training to ensure nursing quality. "More patients come in," said one nurse, "and we are not hiring any more nurses."

Inter-institutional migration or personnel transfers. Nurses moving from one institution to another, due to increases in salary and improvement in working conditions at the community level, was observed in Brazil. In Colombia, inter-institutional migration was generated by the creation of empresas sociales del Estado (State social enterprises), a kind of third-party system. Personnel in Colombia were also being transferred from community settings to tertiary care institutions. Personnel transfers also occurred in Argentina and in the United States, with nurses' work environments increasingly shifting from inpatient to outpatient or community settings. In Argentina, new legislation has allowed the transfer of health workers from provinces to municipalities, with a decreased number of work hours and lower salaries (5).

Flexible employment contracts. Nurses noted changes in employment contracts and job stability, including an increased number of nursing personnel without a definite contract, with a part-time contract, or contracted by projects or programs. A decrease in employee benefits was also reported.

Discrepancies among educational preparation, job titles, and work roles. Some nurses reported administrative reorganization and changes in job titles. Some nurses mentioned reporting to a non-nurse. One nurse said, "Now we have an administrator with no nursing background, just in administrationlevel management." Reductions in clerical positions and in other staff resulted in nurses adding duties previously done by others, such as making appointments and referrals, receiving linens, and managing patient transportation. In the United States, nurses reported increased job responsibilities. One nurse said, "We have more [man- agement] responsibilities delegated to us; they take up a lot more time." Another nurse said: "We're doing more paperwork and a lot less patient care. I don't enjoy it like I used to."

Malpractice concerns. Legal and ethical concerns are reflected in nurses' comments about new or strengthened malpractice worries. Said one nurse: "The voluminous load of paperwork takes you from the patient. You can't get to the patient. We who are the best prepared for patient contact have the least patient contact." Nurses in Colombia reported practicing "defensive care" because clients are more demanding and can more easily sue.

Changes in practice settings. Nurses discussed a number of changes in their practice settings or work environments. In Colombia, there was decreased emphasis on disease prevention and health promotion programs, increased emphasis on hospital care, and decreased emphasis on working in the community. In contrast, disease prevention programs have been expanded in Brazil, with increasing emphasis on community work and decreasing emphasis on hospital care. Home care has increased in the United States and in Brazil.

Other changes in nurses' work environments included organizations shifting their mission from service to enterprise due to serious financial problems, changing emphasis from an individual model to a family-based model, emphasis on prevention or tertiary care, and stressful work environments. With the exception of Colombia, health services have moved from institutional to community settings. Countries have experienced increased acuity in hospitalized patients and increased service demand due to coverage expansion (because of universal coverage in Latin American countries), along with greater emphasis on cost control. Payment systems for patients and providers have changed, with emphasis on reimbursement, stricter reimbursement requirements, and strategies such as managed care. Short hospital stays are common. In addition, 
administrative changes have included the use of organizational matrices, in which nurses appear to report to more than one supervisor or to have responsibilities for more than one area; redistribution of nursing resources; and focus on interdisciplinary teams.

\section{CONCLUSIONS}

Although health care reform has been implemented in the four Latin American countries included in this study and, to a certain degree, in the United States, reform modalities and the extent of reorganization have varied greatly. Our study results are consistent with other current knowledge about health care reform in the study countries. Nevertheless, the intensity of changes has varied among the countries, as have some of the driving forces for change.

In relationship to nursing practice, the study identified a large number of common themes and trends shared by the five countries. In general, nurses report their practice has been influenced by altered personnel mixes or decreases in the nursing workforce, stricter reimbursement mechanisms, health service restraints brought on by economic limitations, new organizational structures, and a changing demographic and health profile for the populations served. The nurses describe doing more work in less time with fewer staff, with sicker populations, and with more restrictions in supplies, equipment, and services.

In nurses' work environments, professional practice arenas have diversified, moving from hospitals to community settings such as clients' homes, businesses, or schools. As the health care environment has become more complex and sophisticated, nurses have had to learn new technologies, work in interdisciplinary teams, adjust to new varieties of health personnel, and become more flexible regarding organizational changes.

The nursing labor market reflects economic trends across the countries to varying degrees. Nurses in the four Latin American countries reported their practice was affected by changes in labor contracts. The influence of the economic crisis on health service was more evident in Argentina than in any other country, and Argentine nurses reported the need to hold two or three jobs in order to support their families. This trend was also present in Brazil, Colombia, and Mexico, although to a lesser extent.

In summary, nurses report changes in their practice and work environments as well as in health service organization, population characteristics and needs, and structural characteristics. Current nursing practice is changing as the work environment is changing, making us wonder: Where do we go from here? From a larger perspective, does the market-driven reorganization of health services conflict with the essence of nursing, which is caring? How do we harmonize the opposites? How do we protect both service providers and clients? How do we regulate an unregulated market?

To answer these questions, additional studies are needed. A study to explore whether the views expressed in this study reflect general nursing viewsand are still current-would be useful. Given the increased workload and the smaller numbers of nursing personnel reported at the study sites, future quantitative studies could examine factors affecting nursing availability and utilization. Studies could further explore nurses' perceptions that recent health service reorganization measures focusing on cost control may be negatively influencing both the quality and the quantity of health service. A specific need exists to examine who is now providing the direct care formerly pro- vided by nurses, and how this is affecting care of the population. Given factors such as the aging of the nursing workforce in most of the countries studied, the insufficient resources, and the job stress and dissatisfaction, there is a need to study nurses' working environment. Educational issues warranting future research include the need for initial and continuing education and for retraining, in order to deal with changes in health knowledge and technology, nursing roles, nursing-practice sites, and ethical and legal concerns. Further study is needed to update information about nursing-practice regulation. These studies would provide vital information for planning nursing systems adjustments that best meet population needs and health service reorganization demands.

Acknowledgements. We extend our thanks to these individuals at the following institutions: Pan American Health Organization (PAHO): Maricel Manfredi, Pedro Brito, Sandra Land, and Edgar Barillas (PAHO consultant); the University of Texas Medical Branch, School of Nursing: Mary Fenton, Elizabeth T. Anderson, Judith C. Drew, and Phyllis N. Goins (retired); Universidad de Buenos Aires, Escuela de Enfermería: Ana María Heredia; Universidad Nacional de Córdoba, Escuela de Enfermería: Stella Felizzia; Universidade de São Paulo, Escola de Enfermagem de Ribeirão Preto: Clarice Aparecida Ferraz and Silvana M. Mishima; Universidad de Antioquia, Escuela de Enfermería: Consuelo Castrillón, Silvia Orrego Sierra, and María Elena Ceballos Velásquez; Universidad Autónoma de Nuevo León, Escuela de Enfermería: María de los Ángeles Paz Morales; and Universidad Juárez del Estado de Durango, Escuela de Enfermería: María Elena Valdez Martínez. This project was funded by PAHO and by the participating institutions in each country.

\section{REFERENCES}

1. World Health Organization. The world health report 1998: life in the 21st century: a vision for all. Geneva: WHO; 1998.
2. Guevara EB, Mendias EP, Goins PN, Drew JC, Heredia AM, Felizzia S, et al. Values unlimited: nurses say human needs come first. Reflections 1998;24(3):17-19.
3. Goins PN. Paradigma de interacción dinámica. In: Guevara EB, Mendias E, eds. La reforma del sector salud y sus implicaciones para la práctica, la regulación y la educación 
de enfermería: un estudio de cinco países. Washington, D.C.: Organización Panamericana de la Salud; 2001. P. 123. (Series HSR 27).

4. Barillas E. Elementos para la reforma del sector salud. Ciudad de Guatemala, Guatemala: Centro Editorial Vile; 1995.

5. Heredia AM, Felizzia S, Piovano M, Bonelli G. La reforma del sector salud y sus implicaciones en la práctica, la regulación y la educación en enfermería en Argentina. In: Guevara EB, Mendias E, eds. La reforma del sector salud y sus implicaciones para la práctica, la regulación y la educación de enfermería: un estudio de cinco países. Washington, D.C.: Organización Panamericana de la Salud; 2001. Pp. 39-66. (Series HSR 27).

6. Ferraz CA, Mishima S. La reforma del sector salud y sus implicaciones en la práctica, la regulación y la educación en enfermería en Brasil. In: Guevara EB, Mendias E, eds. La reforma del sector salud y sus implicaciones para la práctica, la regulación y la educación de enfermería: un estudio de cinco países. Washington, D.C.: Organización Panamericana de la Salud; 2001. Pp. 67-79. (Series HSR 27).

7. Castrillón MC, Orrego S, Pérez L, Ceballos ME. La reforma del sector salud y sus implicaciones en la práctica, la regulación y la educación en enfermería en Colombia. In: Guevara EB, Mendias E, eds. La reforma del sector salud y sus implicaciones para la práctica, la regulación y la educación de enfermería: un estudio de cinco países. Washington, D.C.: Organización Panamericana de la Salud; 2001. Pp. 81-91. (Series HSR 27).
8. Valdez ME. La reforma del sector salud y sus implicaciones en la práctica, la regulación y la educación en enfermería en el estado de México. In: Guevara EB, Mendias E, eds. La reforma del sector salud y sus implicaciones para la práctica, la regulación y la educación en enfermería: un estudio de cinco países. Washington, D.C.: Organización Panamericana de la Salud; 2001. Pp. 93-101. (Series HSR 27).

9. Paz MA, Martínez G. La reforma de salud y sus implicaciones en la práctica, regulación y educación en enfermería en Monterrey, Nuevo León, México. In: Guevara EB, Mendias E, eds. La reforma del sector salud y sus implicaciones para la práctica, la regulación y la educación de enfermería: un estudio de cinco países. Washington, D.C.: Organización Panamericana de la Salud; 2001. Pp. 103-114. (Series HSR 27).

10. Drew J. La reforma del sector salud y sus implicaciones en la práctica, la regulación y la educación en enfermería en los Estados Unidos. In: Guevara EB, Mendias E, eds. La reforma del sector salud y sus implicaciones para la práctica, la regulación y la educación de enfermería: un estudio de cinco países. Washington, D.C.: Organización Panamericana de la Salud; 2001. Pp. 115-128. (Series HSR 27).

11. Guevara EB, Mendias E. La percepción de los enfermeros sobre la reforma del sector salud y los cambios en la práctica de enfermería: temas emergentes en los cinco países. In: Guevara EB, Mendias E, eds. La reforma del sector salud y sus implicaciones para la práctica, la regulación y la educación de enfermería: un estudio de cinco países. Washington, D.C.: Organización Panamericana de la Salud; 2001. Pp. 3-38. (Series HSR 27).

12. Lobiondo-Wood G, Haber J. Nursing research: methods, critical appraisal, and utilization. St. Louis, Missouri, United States of America: Mosby; 2002.

13. Lincoln YS, Guba EG. Naturalistic inquiry. Beverly Hills, California, United States: Sage; 1985.

14. Pan American Health Organization. Health in the Americas. Vol. II. Washington, D.C: PAHO; 1998. (Scientific Publication No. 569).

15. Pan American Health Organization. Health in the Americas. Vol. I. Washington, D.C.: PAHO; 1998. (Scientific Publication No. 569).

16. Anderson OW. Health services in the United States: a growth enterprise since 1875. Ann Arbor, Michigan, United States: Health Administration Press; 1985.

17. Latin America and Caribbean Regional Health Sector Reform Initiative [LACHSR]. Baseline for monitoring and evaluation of health sector reform in Latin America and the Caribbean. Washington, D.C.: Pan American Health Organization; 1997.

18. United States, Department of Health and Human Services. Healthy people 2000: summary report. Boston: Jones \& Bartlett; 1992. (Public Health Services, No. 91-50231).

Manuscript received 28 December 2001. Revised version accepted for publication on 19 August 2002.

RESUMEN Objetivos. Identificar los cambios en la práctica de la enfermería y en el medio donde se ejerce que han tenido lugar con la puesta en marcha de la reforma del sector de la salud (RSS) en cinco países americanos.

Análisis comparativo de los cambios en la práctica de la enfermería relacionados con la reforma del sector de la salud en cinco países americanos
Métodos. Entre 1997 y 1999 se realizó en Argentina, Brasil, Colombia, México y los Estados Unidos de América un estudio exploratorio para obtener los datos narrados por 125 profesionales de la enfermería acerca de sus percepciones de la práctica de la profesión y de los cambios en su ambiente de trabajo. También se obtuvieron descripciones de las características y de las tendencias de la práctica de la profesión en los lugares de trabajo estudiados.

Resultados. En el contexto de la RSS, los cinco países han sufrido una reorganización de los servicios de salud que ha afectado a la práctica de la enfermería. Los participantes de los cinco países mencionaron el aumento de la importancia de la empresa privada; los cambios en el sistema de pago, tanto para los pacientes como para los proveedores; la redistribución de la fuerza de trabajo de los profesionales de la enfermería; los cambios en la composición del personal y en las funciones prácticas de estos profesionales; el cambio del trabajo en el hospital hacia el trabajo en la comunidad, y la mayor importancia prestada en el campo práctico a la prevención y al control de los costos.

Conclusiones. El estudio proporciona información inicial sobre los problemas actuales de la enfermería que han aparecido a consecuencia de las iniciativas de RSS. Los participantes de los cinco países identificaron muchos temas, tendencias y cambios comunes en la práctica de la enfermería, independientemente de las diferencias en los tipos de servicios de enfermería y de la fase de implementación de la RSS en cada país. Las fuerzas que llevaron al cambio y la intensidad de este han sido muy diferentes en los cinco países. Los profesionales de la enfermería siguen manteniendo sus valores esenciales a pesar del mayor estrés laboral, de las mayores necesidades asistenciales de los pacientes y, en los países de América Latina, a pesar de la crisis económica. 